\title{
Neonatal Research: Parent's Perception of Informed Consent
}

Sir,

Clinical research trials require written informed consent to safeguard the child's best interest. Integrity of the process of consent is a matter of great concern. ${ }^{1}$ Formal training of the person taking consent in legal and ethical way, basic level of education of parents and information given about the trial, all play important role. Whether the parents are able to process the information correctly, under the stressful condition and are able to take decision of informed consent, needs to be evaluated. ${ }^{2}$ Moreover, it is important to understand that making decision about the child, needs parents enrollment and it can't be left solely to doctor. ${ }^{3}$

Studies have been done on the perception of parents for the process of consent making in case of clinical trials, especially the randomized trials and neonates enrolled in the multiple research trials..$^{3-4}$ The validity of this process has not been studied in Indian population. As a pilot study, a qualitative analysis of parent's perception of the process of consent when their stable newborn baby was enrolled in low risk, non-randomized project was done.

A prospective analysis was done to evaluate the attitude of parents towards enrollment of their child in neonatal research with the primary objective to find out the parents perception. Parents of apparently healthy neonates not requiring intensive care, born in the month of June-July 2008, enrolled in mass newborn screening project, were interviewed using a pre-designed questionnaire.

A total of 129 parents were interviewed over a period of 30 days. Only mothers were available for the interview and $93 \%$ preferred to answer directly rather than filling the questionnaire. $67 \%$ mothers had urban background and $68 \%$ were at least high school educated. Baby is too small for the research was felt by $43.4 \%$ of the mothers despite the fact that all the mothers felt that trial was safe. $84 \%$ of the mothers had understood the purpose of research and majority of them foud that information provided was complete and adequate. Around $57 \%$ of the mother's felt that care of the child will improve if the child was enrolled in the study. Only $22 \%$ of the mothers were unhappy about delivering in a hospital that does the research and $17 \%$ felt that research will not help anybody. three-fourth of the mothers felt that either their baby alone or babies in future will be at benefit from the research. When asked about that whether they willingly entered in the research or forced for it, then $92 \%$ informed that they consented to be in the research willingly.

Majority, $80 \%$ of parents were of opinion that consent should be taken before their child enters into a clinical trial, even though it is not a randomized trial, and physician plays an important role in the process of consent. Only half of the parents were ready to be enrolled in multiple trials.

Suksham Jain, Deepak Chawla and Anuradha Bansal Department of Pediatrics, Government Medical College and Hospital, Chandigarh, India. E-mail:dr.sukshamj@gmail.com [DOI-10.1007/s12098-010-0109-y]

\section{REFERENCES}

1. Stenson BJ, Becher JC, Mcintosh N. Neonatal research: the parental perspective. Arch Dis Child Fetal Neonatal Ed 2004; 89: F321-F324.

2. Chappuy H, Doz F, Blanche S, Gentet JC, Pons G, Treluer JM. Parental consent in pediatric clinical research. Arch Dis Child 2006; 91: 112-116.

3. Burgess E, Singhal N, Amin H, D D Mc Millan, Devrome H. Consent for clinical reseach in the neonatal intensive cae unit: a retrospective survey and a prospective study. Arch Dis Child Fetal Neonatal Ed 2003; 88: F280-F286.

4. Mason SA, Allmark PJ. Obtaining informed consent to neonatal randomized controlled trials: interview with parents and clinicians in the Euricon study. The Lancet 2000; 356: 20452051.

5. Morley CJ, Lau R, Davis PG, Morse C. What do parents think about enrolling their premature babies in several research studies? Arch Dis Child Fetal Neonatal Ed 2005; 90: F225-F228. 